EGU21-15557

https://doi.org/10.5194/egusphere-egu21-15557

EGU General Assembly 2021

(c) Author(s) 2021. This work is distributed under

the Creative Commons Attribution 4.0 License.

\title{
Ground motion simulations for finite-fault earthquake scenarios on the Húsavík-Flatey Fault, North Iceland
}

\author{
Claudia Abril ${ }^{1}$, Martin Mai ${ }^{2}$, Benedikt Halldórsson ${ }^{1,3}, \mathrm{Bo} \mathrm{Li}^{4}$, Alice Gabriel ${ }^{4}$, and Thomas Ulrich ${ }^{4}$ \\ ${ }^{1}$ Icelandic Meteorological Office - IMO, Reykjavik, Iceland (claudia@vedur.is) \\ ${ }^{2}$ King Abdullah University of Science and Technology - KAUST, Thuwal, Saudi Arabia \\ ${ }^{3}$ University of Iceland, Reykjavik, Iceland \\ ${ }^{4}$ Ludwig Maximilian University, LMU, Münich, Germany
}

The Tjörnes Fracture Zone (TFZ) in North Iceland is the largest and most complex zone of transform faulting in Iceland, formed due to a ridge-jump between two spreading centers of the Mid-Atlantic Ridge, the Northern Volcanic Zone and Kolbeinsey Ridge in North Iceland. Strong earthquakes $(M s>6)$ have repeatedly occurred in the TFZ and affected the North Icelandic population. In particular the large historical earthquakes of 1755 (Ms 7.0) and 1872 (doublet, Ms 6.5), have been associated with the Húsavik-Flatey Fault (HFF), which is the largest linear strike-slip transform fault in the TFZ, and in Iceland. We simulate fault rupture on the HFF and the corresponding near-fault ground motion for several potential earthquake scenarios, including scenario events that replicate the large 1755 and 1872 events. Such simulations are relevant for the town of Húsavik in particular, as it is located on top of the HFF and is therefore subject to the highest seismic hazard in the country. Due to the mostly offshore location of the HFF, its precise geometry has only recently been studied in more detail. We compile updated seismological and geophysical information in the area, such as a recently derived three-dimensional velocity model for $\mathrm{P}$ and $\mathrm{S}$ waves. Seismicity relocations using this velocity model, together with bathymetric and geodetic data, provide detailed information to constrain the fault geometry. In addition, we use this 3D velocity model to simulate seismic wave propagation. For this purpose, we generate a variety of kinematic earthquake-rupture scenarios, and apply a 3D finite-difference method (SORD) to propagate the radiated seismic waves through Earth structure. Slip distributions for the different scenarios are computed using a von Karman autocorrelation function whose parameters are calibrated with slip distributions available for a few recent Icelandic earthquakes. Simulated scenarios provide synthetic ground motion and time histories and estimates of peak ground motion parameters (PGA and PGV) at low frequencies ( $<2 \mathrm{~Hz}$ ) for Húsavík and other main towns in North Iceland along with maps of ground shaking for the entire region [130 km x $110 \mathrm{~km}$ ]. Ground motion estimates are compared with those provided by empirical ground motion models calibrated to Icelandic earthquakes and dynamic fault-rupture simulations for the HFF. Directivity effects towards or away from the coastal areas are analyzed to estimate the expected range of shaking. Thick sedimentary deposits (up to $\square 4 \mathrm{~km}$ thick) located offshore on top of the HFF (reported by seismic, gravity anomaly and tomographic studies) may affect the effective depth of the fault's top boundary and the surface rupture potential. The results of this study showcase the 
extent of expected ground motions from significant and likely earthquake scenarios on the HFF. Finite fault earthquake simulations complement the currently available information on seismic hazard for North Iceland, and are a first step towards a systematic and large-scale earthquake scenario database on the HFF, and for the entire fault system of the TFZ, that will enable comprehensive and physics-based hazard assessment in the region. 